\title{
CLIMATE-SMART INNOVATION TOOL: AN APPROACH TO REVIEW THE CLIMATE RESPONSIVENESS AND INNOVATION PRACTICES OF THE AGRICULTURAL CURRICULA
}

\author{
W. van Staden ${ }^{1}$
}

Correspondence author: W. van Staden. Email: wilmavanstaden@ gmail.com

\begin{abstract}
The dissemination and uptake of climate-smart practices and concepts within the South African education, training and extension services within the agricultural system is still an ongoing and challenging process. The aim of this study was to develop a curriculum review tool to assist agricultural trainers to evaluate and innovate their teaching and learning practices towards climate-smart responsiveness. The review tool is an innovative tool to prioritise climate-smart practices and to support the development of climate responsive extension education. A curriculum review study at Taung Agricultural College revealed variations in the extent of alignment between the curriculum and climate-smart agriculture practices and concepts amongst the departments. The tool assisted staff to identify the climate responsive topics and concepts that were relevant to the subject under review, as well as the climate-smart responsive status of the subject. The study showed that the tool was beneficial for curriculum alignment review and thus for charting out the start of reflexive learning and change processes that are needed to support the incorporation of climate responsive practices into the agricultural systems. The tool also supports agricultural trainers as a climate-smart learning platform for agricultural trainers that introduces new practically applicable concepts and information that fosters the change necessary for community-orientated innovative action.
\end{abstract}

Keywords: Climate-smart agriculture, Curriculum innovation, Extension training

\section{INTRODUCTION}

The dissemination of climate-smart agricultural practise within the local community are critical. Only through training the agricultural trainers and the development of communitybased learning networks can this be possible. An opportunity to develop a climate responsive innovation tool emerged during a time when the Agricultural Training Institutes (ATIs) of the North West Province were striving towards new solutions in response to climate change and inclusion of climate-smart agriculture within the agricultural learning systems and the strategic plan of the province (READ, 2015). The integration of climate-smart agriculture into the education, training and extension services within the agricultural systems were undertaken through curriculum innovation and realignment of the teaching and learning practices. The concern for change and alignment was an opportunity to develop an innovation tool to support the agricultural training staff to focus on climate responsive practices and to apply these practices within the local rural farming communities.

\footnotetext{
${ }^{1}$ Post-Doctoral Research Associate, Environmental Learning Research Centre, Department of Education, Rhodes University, Grahamstown, South Africa, Email: wilmavanstaden@ gmail.com, ORCiD number: 00000002-2794-228x
} 
The Climate-Smart Innovation Tool was developed, as part of a study centred on some of the complexities of innovation in the agricultural learning systems in response to climate change in the North West Province of South Africa (Van Staden, 2018; Van Staden, Lotz-Sisitka \& O'Donoghue, 2018). It developed within the Training of Trainers Amanzi [Water] For Food Project (Water Research Council (WRC), 2017) supported by the Environmental Learning Research Centre (ELRC) of Rhodes University and the Water Research Commission. The Amanzi for Food Project concentrated on knowledge dissemination of sustainable water use and food security through a course activated social learning network approach within the agricultural learning systems (Lotz-Sisitka et al, 2016). These learning systems comprise of agricultural lecturers, extension officers, farmers, and other agricultural community members.

During this study, the National Diploma by the Irrigation of Taung Agricultural College was reviewed by utilising the Climate-Smart Innovation Tool. The effectiveness of an agricultural curriculum is the cornerstone of successful extension programmes (Coleman et al, 2011). The data derived from the tool enabled the ATI's staff to develop a clearer picture of the current curriculum and how to innovate the curriculum towards climate responsive teaching and learning practices aligned with the demands of the agricultural system and development of required responsive competencies within the agricultural community.

\section{CONCEPTUAL FRAMEWORK}

The Climate-Smart Innovation Tool supports innovation at an individual and institutional level. The tool focusses on promoting the integration of climate responsive practices to strengthen farmer capacity, linking agricultural community networks and managing of resources. It is founded within the Innovation System framework informed by the Climate-Smart Agriculture approach and Cultural Historical Activity Theory (CHAT) (Engeström, 1987). Climate-smart agriculture was a focus point for the development of the tool as the North West Province included this approach as part of their climate change responsive Agricultural Strategic Plan (READ, 2015). A climate-smart agricultural approach addresses the challenges of food insecurity and climate change within the agricultural system. It is a strategy for long-term innovation that considers national and local priorities, and challenges focussing on using agricultural resources efficiently, while increasing the agriculture systems' resilience to climate change and shock (Food and Agriculture Organisation of the United Nations (FAO), 2013).

Other examples of curriculum evaluation tools were investigated, and relevant aspects were adapted to produce an innovation tool that could be used throughout the review process. The Norms and Standards for Extension and Advisory Services in the Agriculture Directorate and the Agriculture Education and Training Strategy for Agriculture and Rural Development in South Africa (AET Strategy) were investigated during the development of the tool (Department of Agriculture (DoA), 2005a; DoA, 2005b). During the tool development phase, the Sustainability Assessment Questionnaire (SAQ) (University Leaders for a Sustainable Future (ULSF), 1999), the Auditing Instrument for Sustainability in Higher Education (AISHE) (Roorda, 2001), and Graphical Assessment of Sustainability (GASU) (Lozano, 2006) were examined. However, the study drew mainly upon the Climate Compatible Framework for curriculum innovation developed by, and further guided by Southern African Regional Universities (SARUA, 2014) to identify the climate-smart responsive competencies necessary for systems innovation. SARUA (2014) guided the development of climate-smart agriculture as a responsive tool that could capacitate agricultural trainers and innovate the curriculum through integration of new paradigm thinking, integration of climate-smart 
agricultural knowledge, relevant core competencies, as well as values and ethics incorporated within this approach. Climate-smart agricultural issues such as carbon dioxide emissions, adaptation and resilience towards climate change were also included in the tool (FAO, 2013).

The Climate-Smart Innovation Framework adapted from the Climate Compatible Framework for curriculum innovation developed by SARUA (2014) supported the development of a climate-smart responsive tool that could capacitate staff and innovate the curriculum through integration of new paradigm thinking, integration of climate-smart agriculture knowledge, relevant core competencies, as well as values and ethics incorporated within this approach. The United Nations Environment Programme's Unit-Based Sustainability Assessment Tool model developed by Togo (2009) was used as a guide and was adapted to suit this study to develop an indicator-based assessment tool (Togo \& Lotz-Sisitka, 2009).The Climate-Smart Innovation Tool only focusses on the integration of climate responsive concepts and practices into the agricultural curriculum. Whereas criterion referenced assessment tools such as the Extension Curriculum Assessment Tool focusses on the comprehensive extension education curriculum (Finkbeiner \& Braun, 2012).

\section{METHODOLOGY}

The driving factor for the development of the tool was the need to establish the level of climatesmart agricultural practices, policy and approach integration into the agriculture curriculum throughout the education, training and extension structures within the agricultural system. The tool was developed to support agricultural trainers to innovate their learning programme through learning-led change. The aim was to develop a tool that could enable users to gain an insight into the whole picture of climate-smart responsiveness within the agriculture curriculum, discover new knowledge and practices, and to support and track innovation towards a climate-smart responsive agricultural system. The tool is designed in a way that an individual agricultural trainer, curriculum developer, or manager can use it to review his/her training programme, community engagement, institutional policies, and application of climate responsive competencies through demonstration sites and teaching gardens. For this paper, the Climate-Smart Innovation Tool was used reflexively to develop a clear climate-smart responsive picture of the National Diploma in Agriculture - Irrigation. The score analysis of the Climate-Smart Innovation Tool completed by the college's teaching and management staff provided a climate responsive indicative picture of the Animal Production, Crop Production and Irrigation departments.

The Climate-Smart Innovation Tool with a complete description of all clusters and indicators are available online (Van Staden et al, 2018). The tool is divided into three parts intended to review the climate-smart responsiveness of a specific section of the agricultural training programme activities. Part A deals with teaching approaches that include the theoretical and practical curriculum content's climate-smart responsiveness. It focuses on competencies, research, community engagement, assessment and trainer expertise, and the willingness of the trainer to participate in the process of innovation towards climate-smart responsiveness. Section A comprises of seven indicators. Indicator $\mathrm{C} 1$ focusses on the staff expertise and innovation. Indicator $\mathrm{C} 2$ focusses on the development of climate-smart agricultural awareness competencies. Indicator C3 covers the general climate-smart agriculture topics. Indicator C4 focuses on the assessment of climate-smart agricultural topics, while indicator $\mathrm{C} 5$ focuses on the practical curriculum content and research aspects. Indicator C6 assesses the importance of 
community engagement towards climate responsiveness. Finally, indicator $\mathrm{C} 7$ reviews the integration of climate-smart agriculture within the formal curriculum and training programme.

Part B of the Climate-Smart Innovation Tool pays attention to the climate-smart responsive concepts and principles in the curriculum outline, core competencies, and the curriculum content in relation to a specific area of expertise for each department (Van Staden et al, 2018). Part $\mathrm{C}$ focuses specifically on the institutional functioning of ATIs. Part $\mathrm{C}$ reviews the Agriculture Training Institute's operations and the management of the institute. Part $\mathrm{C}$ also identifies the institute's performance towards climate-smart responsiveness. The tool concludes with the policies and written statements of the institute and its alignment with climate-smart responsiveness and the National Agriculture Strategic Plan for Agriculture Training Institutes (Van Staden et al, 2018).

Table 1 outlines the assessment criteria of the tool. The data presented in this paper are from the college's teaching and management staffs' answers obtained via the tool and not from any additional information. A total of 13 teaching and management staff from Taung Agricultural College completed the Climate-Smart Innovation Tool reviewed in this paper. This was important, as the score analysis were intended to assist teaching and management staff to review their own curriculum to foster further dialogue and discussion towards curriculum innovation (Van Staden, 2018). Section A and B's score analysis for the Department's Plant Production, Animal Production, and Irrigation is discussed below, followed by a management and institutional policies' climate-smart responsiveness review.

Table 1: Assessment criteria used for the Climate-Smart Innovation Tool score analysis

\begin{tabular}{|l|l|l|}
\hline \multicolumn{2}{|l|}{ RATING } & \\
\hline 0 & None & There is no evidence on the indicator. \\
\hline 1 & Unsatisfactory & The indicator does not meet the necessary requirements. \\
\hline 2 & $\begin{array}{l}\text { Needs } \\
\text { development }\end{array}$ & Indicates performance, but improvement is required. \\
\hline 3 & Adequate & Evidence shows adequate climate-smart responsiveness. \\
\hline 4 & $\begin{array}{l}\text { Meets } \\
\text { requirements }\end{array}$ & $\begin{array}{l}\text { Evidence indicates that the climate-smart responsive standard has } \\
\text { been met. }\end{array}$ \\
\hline 5 & $\begin{array}{l}\text { Exceeds } \\
\text { requirements }\end{array}$ & $\begin{array}{l}\text { Evidence indicates that expectations have been exceeded and climate- } \\
\text { smart responsiveness has been successfully attained. }\end{array}$ \\
\hline
\end{tabular}

\section{RESULTS}

\subsection{Climate-Smart Innovation Tool - Crop Production Department}

Four Climate-Smart Innovation Tool booklets, completed by lecturers from the Crop Production Department, were analysed. Figure 1 depicts the average score of all indicators within the clusters and indicates the climate-smart responsiveness of the Crop Production Department. This department scored the highest for indicator cluster $\mathrm{C} 1$ at $40 \%$ (Figure 1). The department's average score for indicator cluster $\mathrm{C} 2$, the development of climate-smart agricultural awareness competencies among students, was $28 \%$ as the curriculum focuses on systems thinking skills and critical thinking skills. Indicator cluster $\mathrm{C} 3$ scored an average of $26 \%$ with only indicator D5 (developing of entrepreneurial skills) scoring high at four. This indicates that the college does focus on developing entrepreneurial skills. For the examination 
and assessment of climate-smart agricultural awareness topics, indicator cluster $\mathrm{C} 4$ scored 5\% with all indicators scoring low, except for E1 (climate responsiveness of examination content). The practical curriculum and research development, indicator cluster C5, scored 23\%. Indicator cluster C6 (community engagement) scored an indicative 32\% and there was no indication that climate-smart agriculture topics were included in the formal curriculum (indicator cluster $\mathrm{C} 7$ scored 0\%). Climate-smart agricultural responsive topics related to crop production tested in Section B scored 30\%. Integrated topics included benefits of mixed farming, sustainable crop management, and indigenous knowledge inclusion. The topics not formally included in the curriculum are resilience to climate change, adaptation to climate change problems and solutions, reduction of carbon footprint, sustainable methods to increase yield, and methods of intensification to reduce agriculture expansion.

\section{Climate-Smart Responsiveness - Crop Production}

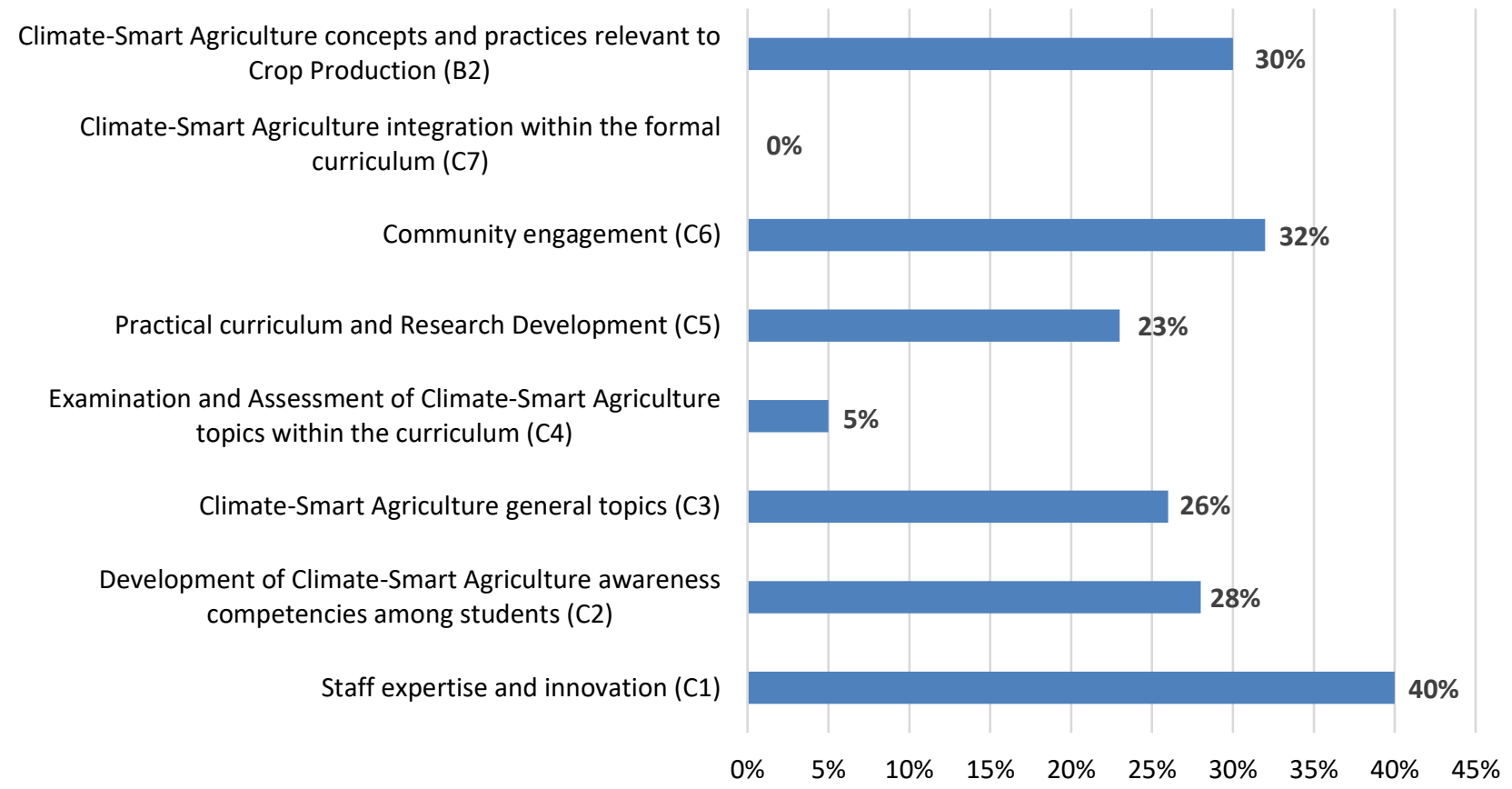

Figure 1: Climate-Smart Innovation Tool - Section A (curriculum, teaching approach, and student-community engagements) and Section B (crop production) calculated average indicator cluster score analysis for crop production

\subsection{Climate-Smart Innovation Tool - Animal Production Department}

The calculated analysis for this section comprises of four Climate-Smart Innovation Tool booklets completed by three lecturers and one Head of Department from the Animal Production Department. Figure 2 illustrates the average indicator cluster score analysis of the Animal Production Department. The department scored a satisfactory $56 \%$ in indicator cluster $\mathrm{C} 2$, developing climate-smart awareness competencies amongst students. Indicator B2, B3 and B4 all scored high at 4 . This indicates that the teaching programme generally focusses on developing competencies within students. The level of staff expertise needs development according to indicator cluster $\mathrm{C} 1$, as this indicator scored $2(40 \%)$. The tool analysis showed that the department is aware that climate-smart agricultural responsive topics should play an 
important part in the curriculum and that the department planned to integrate relevant concepts into the curriculum in the near future.

Indicator cluster C3 (climate-smart general topics) scored an average of $23 \%$. An inclusion of climate related topics within the curriculum were likely as the college curriculum is a relatively new and an informed curriculum. Indicator D5 scored 4, indicating that the department focuses on the development of entrepreneurial skills. The examination and assessment of climate-smart agricultural topics scored low at $15 \%$ (indicator cluster $\mathrm{C} 4$ ). The practical curriculum and research development indicator cluster $\mathrm{C} 5$ indicated the integration of climate-smart responsive topics into the practical components of the curriculum at $29 \%$. This score analysis suggested room for development and innovation within the practical projects and teaching. Indicator F1 indicates that there is no formal research nor research projects in the field of climate-smart agriculture nor climate responsiveness currently running in the department. Cluster C6 (community engagement section) scored the lowest at $12 \%$. Through the scores, one could tentatively conclude that the department is not involved in community initiatives that address climate-smart responsive issues or focused on green job creation, poverty eradication and food security. The integration of climate-smart agricultural responsive topics within the Animal Production Department curriculum content scored 20\% (cluster C7). The indicator from Section B that addresses topics surrounding adapted sustainable livestock and pasture management scored 4, indicating inclusion within the curriculum. Indicators of Section B not formally introduced in the department's learning programme included indigenous knowledge, techniques to enhance livestock farmers' resilience, climate adaptation, reducing carbon footprint, and methods to increase nutrition quality whilst increasing production.

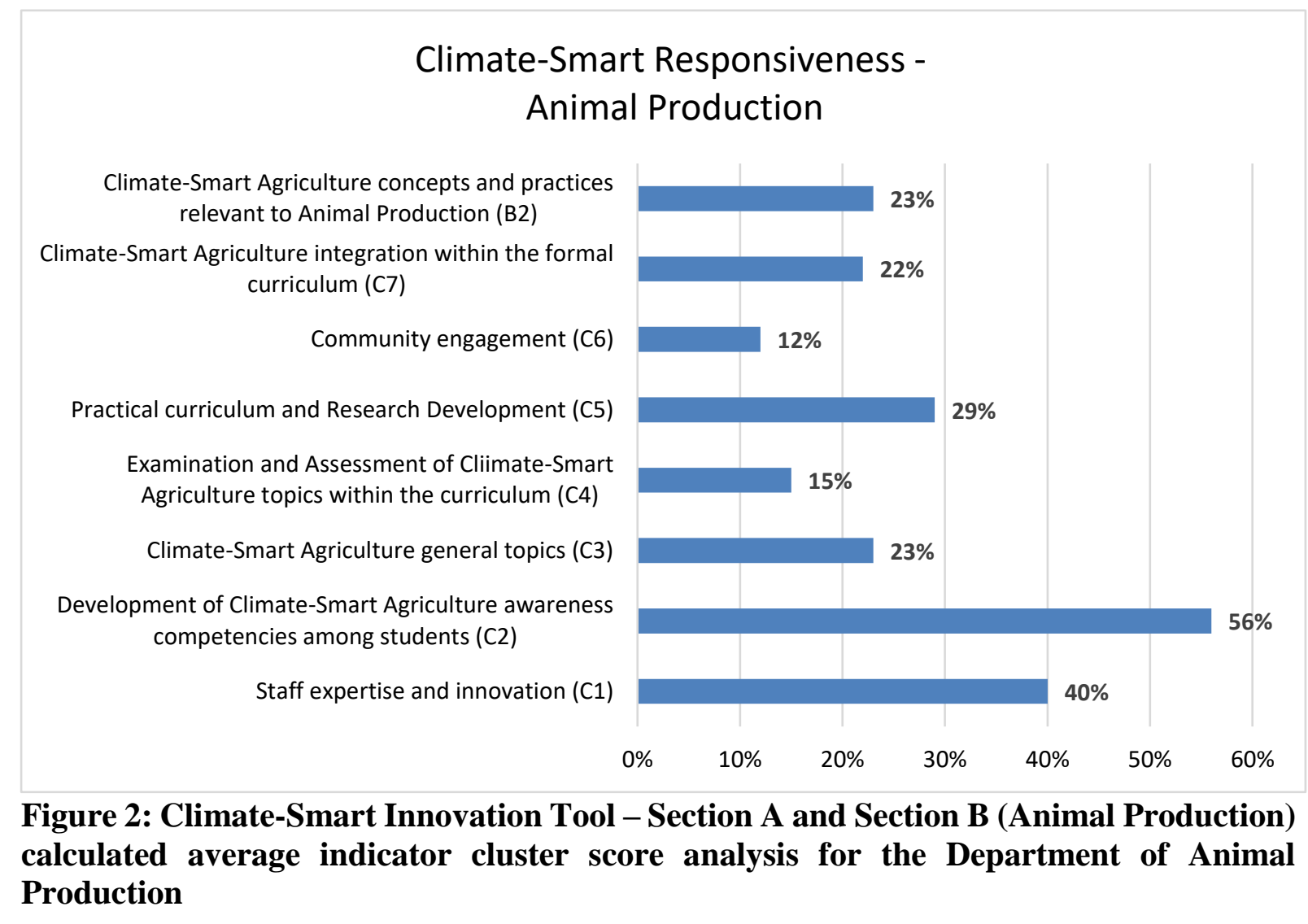




\subsection{Climate-Smart Innovation Tool - Department of Irrigation}

The Irrigation Department review is based on the score analysis of three tools completed by two lecturers and one Head of Department. Figure 3 illustrates the climate-smart responsiveness of the Irrigation Department through average cluster indicator score analysis. Indicator cluster $\mathrm{C} 1$ (staff expertise and innovation) scored the highest at $60 \%$. Indicator A3 and A4 both scored 5, indicating that the staff recognise the importance of integrating climatesmart agriculture into the curriculum and learning practices. The development of competencies among students (indicator cluster C2) scored 33\%, while the inclusion of general climate-smart agriculture topics (indicator cluster C3) scored 11\%. Indicator D5 (development of entrepreneurial skills) scored the highest (3) of all indicators of indicator cluster C3. Indicator cluster C4 (examination and assessment of climate-smart agriculture responsive topics) scored $40 \%$. Indicator cluster C5 (practical curriculum content and research) scored 31\%. Indicators $\mathrm{F} 1$ and F6 within cluster $\mathrm{C} 5$ scored zero, indicating the absence of climate responsive research within the department and no bursaries for studying food security nor water harvesting are available. Indicator G1 scored 4 within the cluster C6 (community engagement). This indicates that, according to the score analysis, the department is engaged in community involvement projects focusing on food security and rural wealth development. Cluster C7 (climate-smart agriculture integration within the formal curriculum) scored an average of 30\%. Cluster B3 (climate-smart agricultural concepts and practices relevant to Irrigation: Natural Resource Management - Water) from Section B of the tool scored 33\%. The indicator reviewing the inclusion of sustainable water management practices within the curriculum and learning practices of the department scored high at $4(80 \%)$.

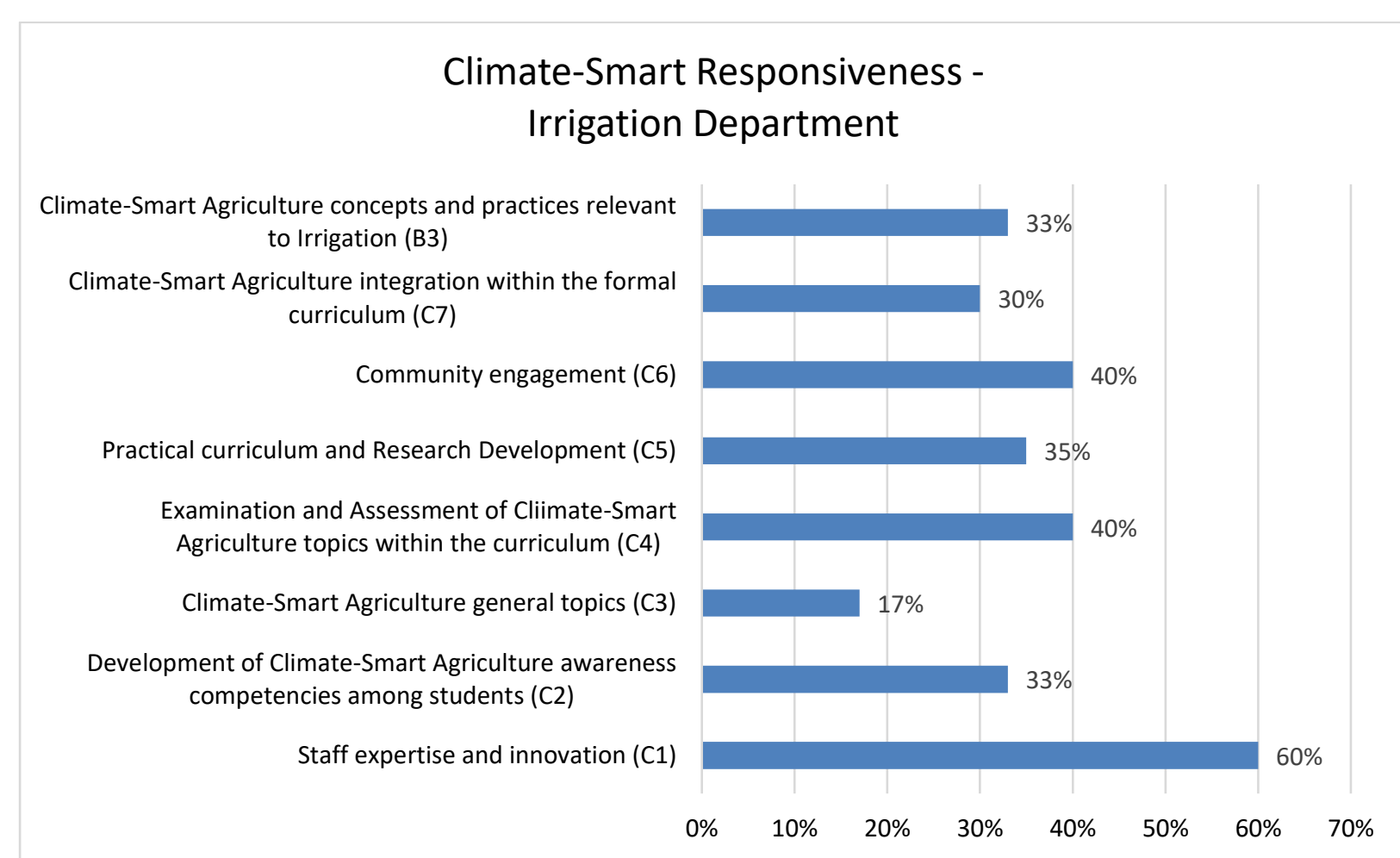

Figure 3: Climate-Smart Innovation Tool - Section A and Section B: Natural Resources - Water (B3) calculated average indicator cluster score analysis for the Department of Irrigation 


\subsection{The management and institutional policies' climate-smart responsiveness}

The National Diploma in Agriculture: Irrigation's overall scores for Section C were average. Section $\mathrm{C}$ reviews the institutional and policy climate responsiveness. The Climate-Smart Innovation Tool - Section C cluster indicators include Curriculum Outline of the National Diploma (Indicator Cluster P1), Operations and Management (Indicator Cluster P2), Student Climate-Smart Agriculture Responsiveness and Participation (Cluster Indicator P3), and Policies and Written Statement (Cluster Indicator P4) (Van Staden et al, 2018). Figure 4 depicts the climate-smart responsiveness of all the indicators within the clusters of Section $\mathrm{C}$ of the Tool. The overall diploma scored the highest in the policies and written statements section (Indicator Cluster P4) at 38\%. The institute scored $2(40 \%)$ in all the indicators within Indicator Cluster P4 (the level of integration of climate-smart agricultural concepts such as sustainability into the existing institutional policies), except for P5 that scored $3(60 \%)$. The positive score indicates that the college is aware of provincial policies that reflect the educational engagement with climate-smart agriculture and responsiveness. It also indicates that climate change issues inform the decision-making process in the institute's policy and structure. Management of the college reflected that the college has a good deal of support to assist in the integration of climate-smart agriculture and climate responsiveness aspects into the diploma. There was integration of sustainability into the existing institutional policies. The vision and mission of Taung Agricultural College is also committed towards climate-smart responsiveness.

The college scored 33\% for Indicator Cluster P1 (curriculum outline and National Diploma) that focuses on the integration of climate-smart responsive concepts into the National Diploma. The assessment indicated that topics such as the sustainable increase of agricultural productivity (Indicator D1), adaptation, building resilience to climate change (Indicator D2), and greenhouse gas emission challenges (Indicator D3) form part of the curriculum as these indicators all scored $2(40 \%)$. The extent to which the curriculum is relevant to farmers and extension officers that face climate change challenges scored 2 (40\%, Indicator D5). However, food security and homestead farming is only covered to a slight extent and scored 1 (20\%, Indicator D4). Indicator D6 scored 1 (20\%) due to a lack of interdisciplinary education and articulation of information between subjects that can link extension education, food security, and climate change. The scores collaborated with the curriculum content. Taung Agricultural College curricula were newly developed in 2014. Therefore, certain topics aligned with climate-smart responsiveness are included in the curriculum. Subjects that are climate-smart agriculture orientated include Natural Resource Management, Soil and Water Conservation, and Rural Development.

The section on operation and management scored $17 \%$. There were no waste reduction practices or recycling practices on the campus at the time of review, as indicated by indicators $\mathrm{O} 1$ and $\mathrm{O} 2$. Indicators $\mathrm{O} 3$ and $\mathrm{O} 4$ scored low at $2(40 \%)$ indicating that the campus is aware of the importance of reducing greenhouse gas emissions and conserving energy. Indicator O5 scored at $3(60 \%)$ as a climate-smart agricultural awareness campaign was initiated in 2016. However, there were no water saving practices, including rainwater harvesting and conservation practices, on campus at the time of the review. Thus, Indicators O6 and O7 scored zero. Indicator Cluster P3 (student climate-smart responsiveness and participation) scored zero on all indicators. 


\subsection{Reflexive tool to review, support and track innovations}

The aim of this study was to develop a reflexive tool that could review, support and track curriculum innovation. The tool allowed the agricultural teaching staff to become aware of how their teaching and learning practices affect the students' awareness and perceptions of the world. The student awareness section in the tool indicated to the staff what climate-smart knowledge and competencies the students require to be climate responsive. The tool assisted agricultural trainers to identify what topics were relevant to the subject under review as well as the climate-smart responsive status of the subject (Van Staden et al, 2018). The Climate-Smart Innovation Tool was shown to be a useful tool for curriculum alignment review and thus for charting out the start of reflexive learning and change processes that are needed to support the incorporation of climate responsive knowledge into the system.

The tool is applicable as a knowledge engagement tool to capacitate lectures by exposing them to new abstract concepts. The tool became a reflexive tool that allows the reviewers to capacitate themselves and innovate their teaching and learning programme towards climatesmart responsiveness. From the Climate-Smart Innovation Tool, an online version of the tool emerged as sub-tools. These sub-tools on the Amanzi For Food (2019) website. The Online Climate-Smart Innovation Tools were developed to assist any agricultural trainers to review individual training, curriculum or extension education programme's climate-smart responsiveness. The tool was utilised as a reflexive tool that provides additional opportunities of self-development of knowledge and competencies through online feedback reports and suggested reading sections.

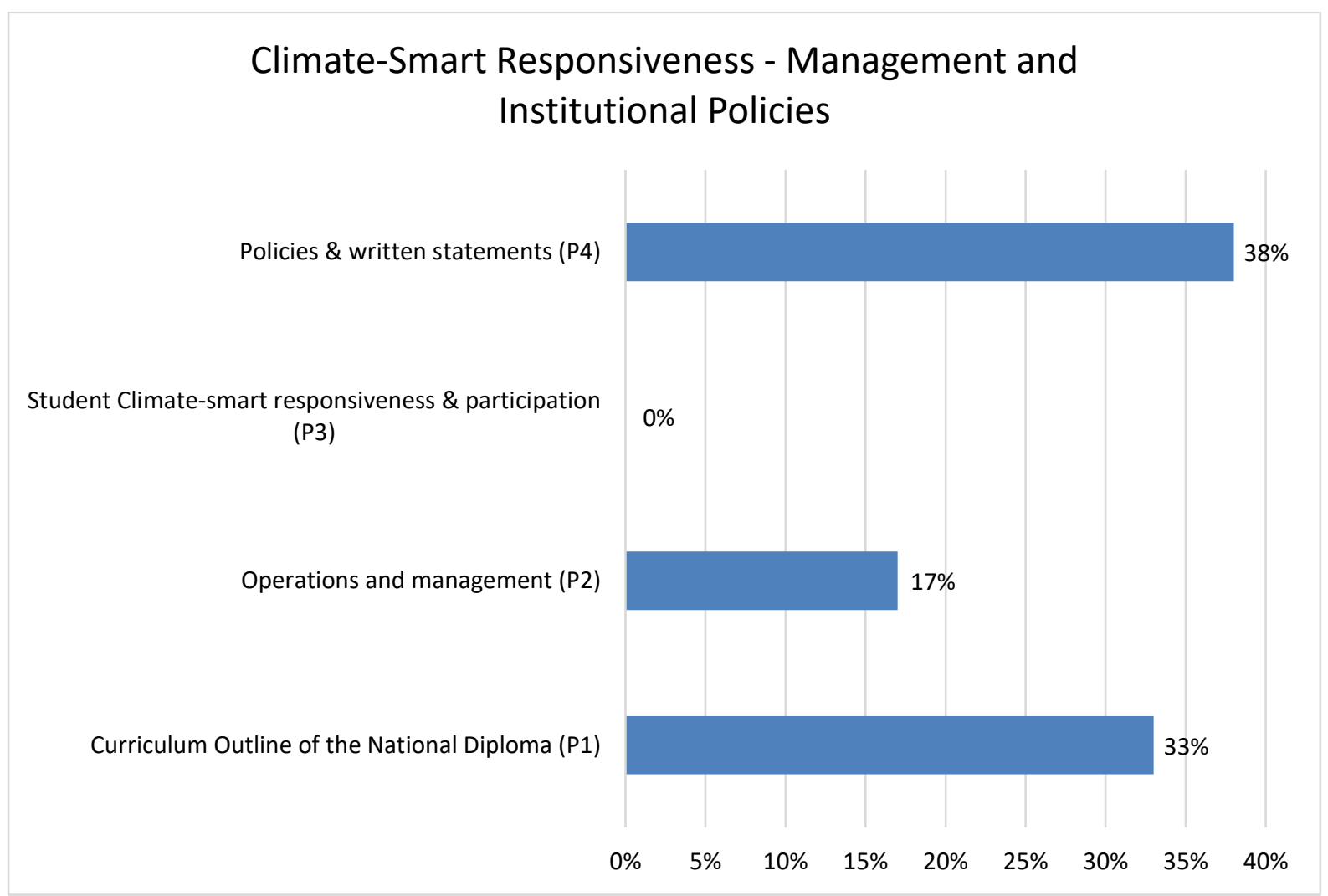

Figure 4: Climate-smart responsiveness of the management and institutional policies of Taung Agricultural College 


\section{DISCUSSION}

This study was developed as a supported process of climate-smart Innovation that examines curriculum and learning system responses to climate change and food insecurity within the Provincial Agricultural Innovation System. The inclusion of climate-smart concepts into the agriculture curriculum is a way to prepare future farmers to ensure food security and regional climate responsiveness. Post-schooling education is a critical contributor to this goal as many of the students who graduate from the ATIs ultimately work as agriculture extension workers or become farmers themselves (SARUA, 2014).

The climate-smart innovation curriculum review revealed variations in the extent of alignment between the curriculum and climate-smart agricultural practices and concepts amongst the departments. The curriculum under view is a fairly new established curriculum, developed in 2014. Thus, the diploma is relatively aligned with the needs of the agricultural system. However, as climate-smart agriculture has only recently been introduced into the system, since 2015 (Van Staden, 2018), it is not surprising that climate-smart agriculture absences within the system were identified. The Climate-Smart Innovation Tool analysis developed a clear picture of the climate-smart responsiveness of the National Diploma of Agriculture - Irrigation. The tool data highlighted that climate-smart concepts such as climate change, food security, water conservation, adaptation, and building resilience to climate change are not directly part of the curriculum of Taung Agricultural College.

All departments that participated in this study indicated a willingness to partake and support curriculum innovation towards climate-smart responsiveness. Thus, the commitment of the staff to initiate change indicates the importance of a tool that can support agricultural trainers during innovation within the agricultural research, training, and extension sub-systems towards a climate-smart system. A climate-smart agricultural approach is a functional response to climate change and can help to lead engagement and curriculum innovation. Since this review, the agricultural college staff has implemented rainwater harvesting and conservation practices on campus, developed a learning network within the community alongside Amanzi for Food (2019), and integrated more climate change awareness practices into the curriculum. This study indicated that the approach is not too complex to understand, and participants showed a willingness to engage with the approach through the Climate-Smart Innovation Tool.

Through the use of the tool, it became evident that the agricultural trainers need support to design, develop and produce new climate-smart responsive content for the curriculum and the corresponding teaching and learning practices to reach the gap between the research-trainingextension knowledge triangle (Academy of Science of South Africa (ASSAf), 2017). The agricultural trainers do not always have access to or time for the new agricultural developments and research, as the colleges are not research institutes. Newly appointed trainers do not necessarily have an academic background in agriculture nor practical experience, a finding also reported in the Eastern Cape Province, especially when it comes to new areas of study that have not previously been included in the agricultural college curricula such as rainwater harvesting, conservation practices, and climate change (Lotz-Sisitka et al, 2016). However, if the trainers and curriculum developers do not have the necessary competencies, knowledge and tools, or transformative agency, initiating innovation towards a climate-smart system is not possible or very difficult, as was reported by Togo (2009) and Agbedahin's (2016) studies on sustainability in higher education. In such a context, professional development programmes for agricultural trainers become important, but there are often too few of these available, especially in new 
areas of study such as climate-smart agriculture (Van Staden, 2018). This is where tools, especially online review tools, can be used to improve skills' development and training of agricultural trainers. As previous studies have indicated, the training of trainers is a priority. The training of extension workers should receive substantial focus. They are the agents that translate the research and training to the agricultural community (ASSAf, 2017).

The development of tools such as the Climate-Smart Innovation Tool supports the uptake of new knowledge and skills into extension education. Different sections of the tool and online tools can be used by any agricultural trainer, including extension officers, to review a curriculum, a practical teaching garden lesson, practices implemented in a demonstration site, or the content of a trainer of trainers' workshop. Through a self-review process supported by the Climate-Smart Innovation Tool as a reflexive and knowledge stimulus tool, the reviewer can visualise the potential expansions of the curriculum and learning practices, thus allowing the reviewer to identify the challenges, dynamics, practices, and teaching methodology that require transformation or revision as aligned with the expansive learning cycle (Engeström, 1987).

\section{CONCLUSION}

The inclusion of climate-smart agriculture into the agricultural education system is of utmost importance. Over the years, the need within the curriculum has developed and changed. Knowledge and competencies relating to sustainability and climate responsiveness require integration into the agricultural research-training-extension knowledge triangle (ASSAf, 2017). For the implementation of new knowledge and competencies within the curriculum and learning practices, the agricultural trainers, including the extension and rural development officers within the system, need to be trained in the new practices, learning and teaching topics (DoA, 2005a; DoA 2005b; DAFF, 2008).

The development of the tool, and online tools, was part of a broader study of the journey of innovation and to increase climate responsiveness of the agricultural education system. The aim of the Climate-Smart Innovation Tool's score analysis was to stimulate reflexivity and further discussions towards curriculum innovation. The tool supports the college staff during curriculum innovation within the curriculum and learning activity system towards a climate responsive system. Since this analysis, the college has initiated various curriculum innovations and participated in climate responsive training.

The Climate-Smart Innovation Tool, based on suitable indicators and clear targets, refocuses the curriculum relevance to farmers and extension officers facing climate change, whilst capacitating trainers to develop and coordinate their training programme. The Climate-Smart Innovation Tool is a tool for charting out the start of reflexive learning and change processes that are required to support the incorporation of climate responsive knowledge into the agricultural research-training-extension triangle. The tool can assist in reporting the responsiveness of the system, be used as a reflexive knowledge engagement aid, while also evaluating the institutional functioning within the system. The tool is a step in the right direction to provide agricultural trainers with a way to self-evaluate and review their innovation practices to prioritise the integration of climate-smart practices in South Africa. 


\section{REFERENCES}

ACADEMY OF SCIENCE OF SOUTH AFRICA (ASSAf), 2017. Revitalising agricultural education and training in South Africa. Pretoria, South Africa.

AGBEDAHIN, A.V., 2016. A morphogenic and laminated system explanation of positionpractice systems and professional development training in mainstreaming education for sustainable development in African universities. PhD Thesis, Rhodes University.

AMANZI FOR FOOD, 2019. CSIT Resources. Available from: http://amanziforfood.co.za/csit-resources/

COLEMAN, G., BYRD-BREDBENNER, C., BAKER, S. \& BOWEN, E., 2011. Best practices for extension curricula review. J. Ext., 49(2):1-5.

DEPARTMENT OF AGRICULTURE (DoA), 2005a. Norms and standards for extension and advisory services in agriculture directorate: Scientific research and development. Available from: http://www.nda.agric.za/doadev/sidemenu/nationalextensionsupport/docs/norms_and standard_booklet.pdf

DEPARTMENT OF AGRICULTURE (DoA), 2005b. AET Strategy - National education and training strategy for agriculture and rural development in South Africa. Pretoria, South Africa.

DEPARTMENT OF AGRICULUTURE, FORESTRY AND FISHERIES (DAFF), 2008. Evaluation of agricultural education and training curricula in South Africa. Pretoria, South Africa.

DEPARTMENT OF RURAL, ENVIRONMENT AND AGRICULTURAL DEVELOPMENT (READ), 2015. Department of Rural, Environment and Agricultural Development North West Provincial government Strategic Plan 2015-2020 PR117/2015

ENGESTRÖM, Y., 1987. Learning by expanding: An activity-theoretical approach to developmental research. Helsinki: Orienta-Konsultit.

FINKBEINER, N. \& BRAUN, B., 2012. University of Maryland extension curriculum assessment tool. Maryland: University of Maryland Extension.

FOOD AND AGRICULTURE ORGANISATION OF THE UNITED NATIONS (FAO), 2013. Climate-Smart agriculture sourcebook. Rome, Italy.

LOTZ-SISITKA, H., PENSANAYI, T., WEAVER, K., LUPELE, C., SISITKA, L., O'DONOGHUE, R., SITHOLE, P., VAN STADEN, W., MABEZA, C., DENISON, J. $\&$ PHILIPS, K., 2016. Water use and food security: Knowledge dissemination and use in agricultural colleges and local learning networks for homestead food gardening and smallholder farming. WRC Report No. 2277/1/16. Pretoria, South Africa.

LOZANO, R., 2006. A tool for a Graphical Assessment for Sustainability in Universities (GASU). J. Clean. Prod., 14(9-11):963-972.

ROORDA, N., 2001. AISHE: Auditing Instrument for Sustainability in Higher Education. Dutch Committee on Sustainable Higher Education. Rotterdam, Netherlands.

SOUTHERN AFRICAN REGIONAL UNIVERSITIES (SARUA), 2014. Climate change counts: Strengthening university contributions to climate compatible development. Available from: www.sarua.org 
TOGO, M., 2009. A systems approach to mainstreaming environment and sustainability in universities: The case of Rhodes University, South Africa. PhD Thesis, Rhodes University.

TOGO, M. \& LOTZ-SISITKA, H., 2009. Unit based sustainability assessment tool. A resource book to complement the UNEP Mainstreaming Environment and Sustainability in African Universities Partnership. Howick: Share-Net.

UNIVERSITY LEADERS FOR A SUSTAINABLE FUTURE (ULSF), 1999. Sustainability assessment questionnaire (SAQ) for colleges and universities. Washington, D.C., United States of America.

VAN STADEN, W., 2018. A review of Climate-Smart system innovations in two Agricultural Colleges in the North West Province in South Africa. PhD Thesis, Rhodes University.

VAN STADEN, W., LOTZ-SISITKA, H. \& O’DONOGHUE, R., 2018. Climate-Smart Innovation Tool. A curriculum innovation support tool for the agricultural learning systems. Available from: http://amanziforfood.co.za/csit-resources/

WATER RESEARCH COUNCIL (WRC), 2017. Amanzi (water) for Food: Developing a social learning network approach to knowledge dissemination and uptake in the agricultural learning system, focusing on the management, use and conservation of water for small scale farming and household food production. Project No. K5/2271. Pretoria, South Africa. 
